\title{
Dimensions de la diversité des maïs indigènes au Mexique
}

Dimensions of native maize diversity in Mexico

Dimensiones des la diversidad de maíces nativos en México

\section{Cecilio Mota Cruz}

\section{(2) OpenEdition}

Journals

Édition électronique

URL : https://journals.openedition.org/ethnoecologie/7453

DOI : $10.4000 /$ ethnoecologie.7453

ISSN : 2267-2419

Éditeur

Laboratoire Éco-anthropologie

Référence électronique

Cecilio Mota Cruz, "Dimensions de la diversité des maïs indigènes au Mexique », Revue

d'ethnoécologie [En ligne], Supplément 2 | 2021, mis en ligne le 25 novembre 2021, consulté le 20 décembre 2021. URL : http://journals.openedition.org/ethnoecologie/7453 ; DOI : https://doi.org/ 10.4000/ethnoecologie.7453

Ce document a été généré automatiquement le 20 décembre 2021.

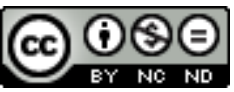

Revue d'ethnoécologie est mis à disposition selon les termes de la licence Creative Commons Attribution - Pas d'Utilisation Commerciale - Pas de Modification 4.0 International. 


\title{
Dimensions de la diversité des maïs indigènes au Mexique
}

\author{
Dimensions of native maize diversity in Mexico \\ Dimensiones des la diversidad de maíces nativos en México
}

\author{
Cecilio Mota Cruz
}

\section{Introduction}

1 Le maïs est actuellement la graminée la plus produite au monde, dépassant les deux autres céréales importantes pour l'humanité : le blé et le riz (FAOSTAT 2018). Au niveau mondial, il est utilisé comme source de biomasse pour le fourrage mais également, dans certains pays, à des fins industrielles et pour la consommation humaine directe; il est aussi utilisé de manière indirecte (sous forme de protéines animales ou de produits transformés) dans pratiquement toutes les régions du monde.

2 Sa diversité génétique a permis sa culture à grande échelle, plus que pour toute autre espèce domestiquée, sous pratiquement toutes les latitudes et altitudes de la planète où l'agriculture est possible. Son cycle annuel et ses caractéristiques de reproduction, notamment le fait que les gamètes mâles et femelles se situent dans des organes séparés (la panicule et l'épi), ont facilité la sélection et la formation rapides, c'est-à-dire en relativement peu de générations, de matériel génétique qui, combiné à une gestion agronomique intensive, a permis d'atteindre le rendement le plus élevé pour une plante cultivée.

3 La graine, organe principalement exploité, a une composition complexe et de nombreux produits industriels, utilisés en maints domaines de la vie moderne en sont issus (Smith et al. 2004).

4 Le Mexique est considéré comme le centre d'origine et de diversification du maïs puisque c'est là que des plants sauvages connus sous le nom de téosintes furent domestiqués, il y a 10000 ans. Les agriculteurs et leurs familles entretiennent actuellement, dans leurs champs et leurs réserves, une grande diversité morphologique 
et génétique de cette céréale dont les semences sont cultivées, sélectionnées et conservées année après année, dans des environnements très variés et pour de nombreux usages, principalement alimentaires. Pour la population mexicaine, il s'agit de l'aliment de base formant une cuisine riche dans toutes les régions, il est aussi le fondement de leur culture. Le maïs est également utilisé dans l'industrie et l'élevage (Bonfil 2012).

\section{Importance du maïs au Mexique}

5 Au Mexique, le maïs occupe un peu plus de la moitié (51\%) de la surface nationale cultivée ; il génère environ $8 \%$ du volume de la production agricole, ce qui représente $30 \%$ de la valeur totale de la production agricole nationale (SIAP 2008). Sur près des huit millions d'hectares destinés à sa culture, $85 \%$ sont en culture pluviale et $15 \%$ en culture irriguée (SIAP 2008).

6 Trois millions de personnes se consacrent à sa culture (Polanco \& Flores 2008), ce qui représente environ $40 \%$ de la main-d'œuvre agricole, c'est-à-dire près de $8 \%$ de la main-d'œuvre totale du pays (Mera 2009). Par ailleurs $85 \%$ des exploitations possèdent une superficie inférieure ou égale à cinq hectares, alors que le reste des agriculteurs (15\%) cultivent sur de plus grandes superficies (SIAP 2008).

7 Environ 21 millions de tonnes de maïs ont été produites par an au cours de la dernière décennie (SIACON 2014). Près de $50 \%$ (10,5 millions de tonnes) du volume produit dans le pays est destiné à la consommation directe de la population urbaine et rurale, principalement sous la forme de tortilla (SIAP 2008), équivalant au pain en Europe. En fonction de l'âge, du sexe, du milieu (rural ou urbain) ou de la classe sociale, la consommation de cet aliment varie entre 200 et $400 \mathrm{~g}$ par jour par personne (Levy et al. 2003) et représente $38,8 \%$ des protéines, $45,2 \%$ des calories et $49,1 \%$ du calcium de l'apport quotidien (Retes 2010).

8 À partir de cette céréale sont préparés au Mexique plus de 600 mets (tamales, atoles, pinoles, pozole, boissons non alcoolisées, boissons fermentées, etc.) (Echeverría \& Arrollo 2000). On utilise pour la construction, l'artisanat ou comme combustible, d'autres parties de la plante telles que les tiges. Ces dernières avec les feuilles servent de fourrage alors que les spathes (appelés totomoxtle au Mexique) permettent d'emballer des aliments. La panicule est également utilisée dans certaines préparations alimentaires tout comme le champignon du maïs (Ustilago maydis) ou huitlacoche, une maladie de la plante, qui est consommé comme friandise dans certaines régions. Le rachis sert quant à lui pour l'artisanat ou comme combustible (Bonfil 2012).

\section{Botanique}

9 Le maïs (Zea mays ssp. mays) est une Poacée (ex Graminée) apparentée aux herbes sauvages des genres Tripsacum et Zea et c'est à partir de ce dernier que s'est faite la domestication puis la mise en culture. Les genres Tripsacum et Zea forment la sous-tribu des Tripsacinae, dans la tribu des Andropogenae, de la famille des Poaceae (Clayton 1973).

Ces genres sont endémiques du Nouveau Monde et leur diversité s'est créée au Mexique (Wilkes 2004). Ils se caractérisent par un métabolisme photosynthétique $\mathrm{C} 4$, ce qui les rend efficaces dans l'utilisation de l'énergie solaire (Eubanks 2006) et, contrairement au 
reste des Poacées, ils présentent des organes mâles et femelles différenciés et séparés sur la même plante (Galinat 1963).

\section{Tripsacum}

11 Le genre Tripsacum regroupe des plantes vivaces diverses possédant différents niveaux de ploïdie, de reproduction sexuée, asexuée ou relevant de l'apomixie (Berthaud et al. 1997). Il comprend 20 taxons répartis du nord-est des États-Unis au Paraguay, dont 16 se trouvent au Mexique (Wilkes 2004). La différenciation des structures mâles (fleurs staminées) et femelles (fleurs pistillées) regroupées dans la même inflorescence ou épi terminal (Galinat 1963) est caractéristique de ces plantes (Figure 1).

Figure 1 : Tripsacum sp., téocinte (Zea mays ssp. mexicana) et maïs (Z. mays ssp. mays). Structure de la fleur mâle $\left(\sigma^{7}\right)$ et de la fleur femelle (ㅇ)
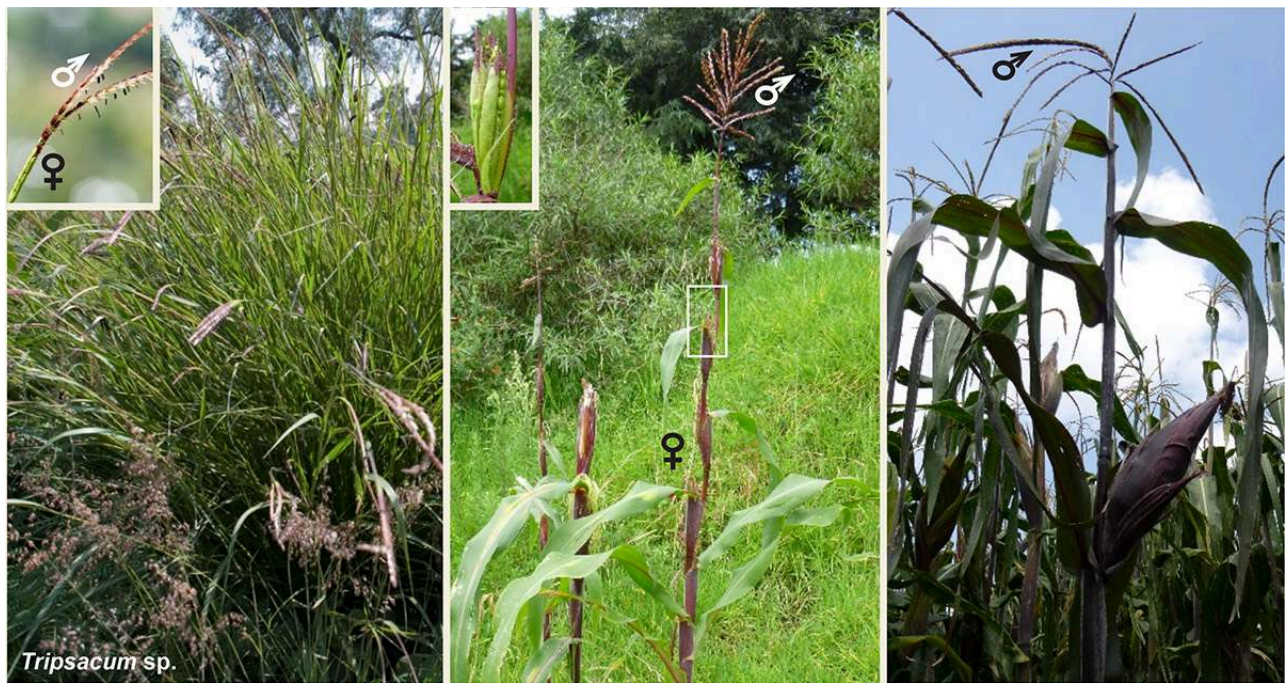

(c) J.M. Martínez \& C. Mota

Les espèces de ce genre peuvent être croisées avec le maïs en utilisant des techniques artificielles ou en utilisant le téosinte comme intermédiaire. Elles sont une source de diversité génétique en termes d'apomixie, favorisant la résistance aux maladies et à la sécheresse. On en produit également des biocarburants (Berthaud et al. 1997, Eubanks et al. 2012).

\section{Zea}

13 Le genre Zea comprend un ensemble d'espèces annuelles et vivaces portant le nom générique de «teocintles» (Zea spp.), ainsi que les espèces domestiquées connues sous le nom de maïs-Zea mays ssp. mays (Iltis \& Dobley 1980). Les deux sont caractérisées par des structures reproductrices sur la même plante, mais séparées en différentes inflorescences (Figure 1) : les fleurs mâles sont groupées dans la panicule et les fleurs femelles qui, une fois fécondées donnent naissance à des grains, sont concentrées dans l'épi (Galinat 1963). Les téosintes et le maïs sont interféconds de manière naturelle et ont des descendants fertiles (Ellstrand et al. 2007). Les téosintes sont distribués de manière irrégulière du nord du Mexique jusqu'au nord-est du Costa Rica mais c'est dans cette zone que l'on en trouve une plus grande diversité (Tableau 1). 
Tableau 1 : Classification et distribution des espèces et sous-espèces du genre Zea

\begin{tabular}{|c|c|c|}
\hline Espèces/sous-espèces & Ploïdie & Distribution \\
\hline \multicolumn{3}{|l|}{ Section Luxuriantes } \\
\hline Zea perennis (Hitch.) Reeves \& Mangelsdorf & $2 n=40$ & Mexique: Colima, Michoacán \\
\hline Zea diploperennis IItis, Doebley \& Guzmán & $2 n=20$ & Mexique: Jalisco, Nayarit \\
\hline Zea luxurians (Durieu \& Ascherson) Bird & $2 n=20$ & Mexique: Oaxaca, Chiapas; Guatemala, El Salvador, Honduras \\
\hline Zea nicaraguensis Iltis \& Benz & $2 n=20$ & Nicaragua \\
\hline Zea vespertilio Gómez-Laurito & & Costa Rica \\
\hline \multicolumn{3}{|l|}{ Section Zea } \\
\hline \multicolumn{3}{|l|}{ Zea mays $\mathrm{L}$. } \\
\hline $\begin{array}{l}\text { Zea mays subsp. huehuetenangensis (Iltis \& Doebley) } \\
\text { Doebley }\end{array}$ & $2 n=20$ & Guatemala \\
\hline Zea mays subsp. mexicana (Schrader) Iltis & $2 n=20$ & Mexique: \\
\hline Race Nobogame & & Chihuahua, Durango \\
\hline Race Durango & & Durango \\
\hline Race Mesa Central & & Jalisco, Michoacán, Guanajuato, Querétaro \\
\hline Race Chalco & & Michoacán, État de México CDMX, Hidalgo, Puebla, Oaxaca \\
\hline Zea mays subsp. parviglumis Iltis \& Doebley & $2 n=20$ & Mexique: Nayarit, Jalisco, Michoacán, Guerrero, Morelos, Oaxaca \\
\hline Zea mays subsp. mays Iltis \& Doebley & $2 n=20$ & $\begin{array}{l}300 \text { races à l'échelle mondiale, } 220 \text { sur le continent américain, } 65 \text { au } \\
\text { Mexique }\end{array}$ \\
\hline
\end{tabular}

Basé sur Iltis \& Doebley 1980, Rivera et al. 2019, Sánchez et al. 2018 et Wilkes 2004).

14 Les téosintes ressemblent beaucoup au maïs, à tel point que dans un champ au Mexique les agriculteurs confondent les deux plantes. Les principales différences résident dans : 1) L'architecture des plantes : le téosinte, selon les conditions de croissance, peut avoir plusieurs tiges secondaires avec des branches qui développent de nombreuses infrutescences et panicules alors que le maïs présente une tige robuste - bien que certaines races puissent présenter plusieurs tiges secondaires - avec un ou plusieurs épis.

2) Les organes de reproduction femelles: l'infrutescence du téosinte mesure huit centimètres de long et est constituée de deux rangées alternées de grains, chaque grain étant enfermé dans une structure durcie (« capsule de fruits ») qui se désintègre lors de la maturation par un mécanisme naturel de dispersion. En ce qui concerne le maïs, l'infrutescence a évolué vers une structure (épi) de plusieurs rangées de grains, enveloppée dans de nombreuses spathes, nécessitant un effort manuel ou mécanique pour détacher le grain (Iltis \& Doebley 1980, Wilkes 2004) (Figure 1).

\section{Domestication en Mésoamérique}

Le maïs est une plante qui n'existe pas en tant que telle dans la nature. Les données rassemblées suite aux recherches menées en botanique (Iltis \& Doebley 1980, Wilkes 2004), en archéobotanique (Benz 2001) et en génétique (Matsuoka et al. 2002), indiquent que les anciens habitants de Mésoamérique ont domestiqué des plantes sauvages du genre Zea ou téosinte (Beadle1972, Kato et al. 2009), correspondant probablement à deux populations de la sous-espèce Zea mays ssp. parviglumis poussant dans le bassin du fleuve Balsas, une région des zones tropicales sèches du centre-est du Mexique (Matsuoka et al. 2002).

La grande réussite de la sélection des plantes de téosinte présentant des différences minimes mais essentielles, telles que des grains exposés et attachés les uns aux autres, fut décisive pour progresser vers la domestication et peu à peu vers un rôle 
prépondérant du maïs dans l'alimentation sur le long terme. On estime que le processus aurait pu commencer il y a environ 10000 ans, selon des données génétiques (Matsuoka et al. 2002) et selon des restes microbotaniques (phytolithes, grains de pollen) retrouvés dans des abris et des grottes (Piperno et al. 2009). Cependant, c'est depuis 6000 ans seulement que le maïs est réellement cultivé et est devenu un aliment important dans les peuplements humains pratiquant une agriculture plus permanente (Benz 2001, MacNeish 1967).

17 Au Mexique, la culture du maïs a donné naissance à des paysages, des technologies et des savoir-faire agricoles ; les sociétés se sont organisées au rythme des cycles de semis, de floraison et de récolte. Cette céréale est devenue la base de la culture alimentaire et a été à l'origine de manifestations artistiques. Son importance était telle que de nombreuses sociétés l'ont déifiée (Figure 2). Le développement des civilisations mésoaméricaines ne pourrait, d'ailleurs, pas être compris sans prendre en compte cette base matérielle de subsistance (Bonfil 2012). Sa mise en culture, à travers le territoire mésoaméricain soumis à des environnements très divers, a conduit à sa diversification en différents types dispersés du nord au sud du continent américain. De telle sorte qu'à son arrivée en Europe au tout début du Xvi ${ }^{\mathrm{e}}$ siècle, le maïs était déjà cultivé du sud du Canada jusqu'à l'île de Chiloé (Staller et al. 2006, Taba 1995).

Figure 2 : Déesse Chicomecóatl. Museum de l'Ex-Convento Culhuacán, Ville de México

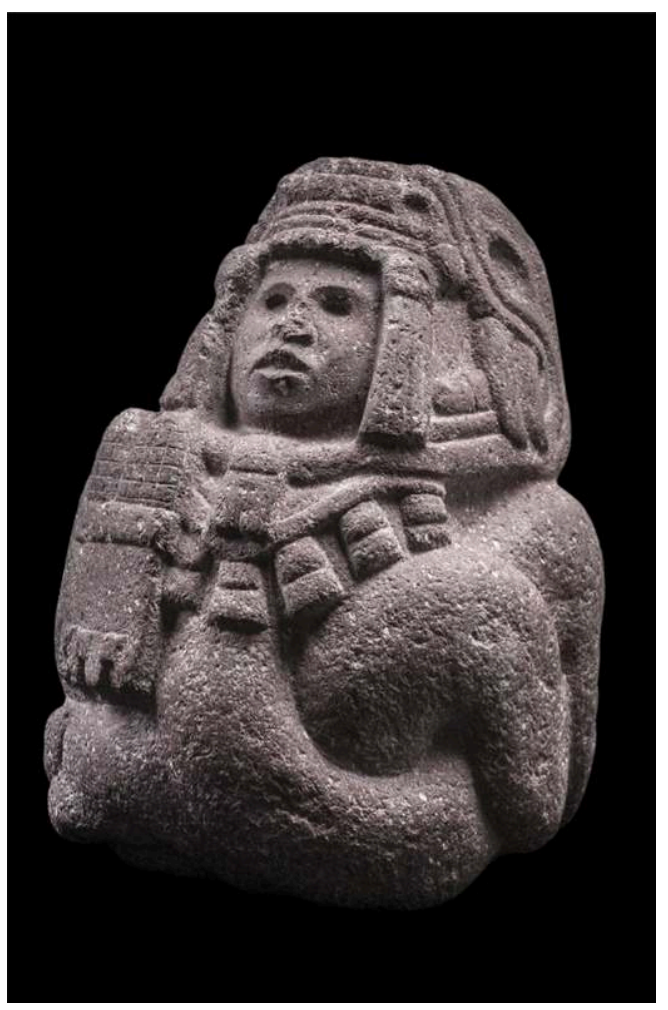

\section{Études sur la connaissance du maïs indigène au Mexique}

Des documents des XVI ${ }^{\mathrm{e}}$ au XIX ${ }^{\mathrm{e}}$ siècles (Sahagún 1975, Hernández 1942, Humboldt 1985) soulignent la pertinence et l'importance du maïs dans la culture, l'alimentation, 
l'agriculture et l'économie du Mexique. Cependant, ce n'est qu'au $\mathrm{xx}^{\mathrm{e}}$ siècle que sont menées des études systématiques sur sa diversité. Chávez en 1913 publie la première monographie concernant les principaux types de maïs. Entre 1925 et 1927, l'expédition russe de S.M. Bukasov et Nicolai I. Vavilov a permis de récolter et d'étudier des maïs indigènes du Mexique, du Guatemala et de Colombie, reconnaissant ainsi «l'immense variabilité » des matériaux mexicains (Kuleshov 1930).

Dans les années 40, le Departamento de Campos Experimentales, de la Secretaría de Agricultura (Département des Champs Expérimentaux du ministère de l'Agriculture) mène des travaux d'amélioration génétique du maïs en essayant d'introduire des hybrides provenant des États-Unis. Toutefois, en raison du manque d'adaptation de ces derniers, ce sont les maïs locaux qui sont collectés et étudiés, réalisant ainsi d'importants progrès et générant de nouvelles semences à partir du matériel génétique des races Celaya et Bolita qui serviront ensuite de base pour la création des maïs améliorés (Limón 1945).

Anderson (1946) recueille, étudie et décrit le maïs de différentes régions du Mexique, notamment du centre et de l'ouest, et propose, avec Cutler (1942), le concept de race, ainsi que les critères et caractères descriptifs pertinents pour la classification raciale des populations de maïs à pollinisation libre. Ce concept est utilisé jusqu'à aujourd'hui dans les études sur la diversité du maïs indigène. Il s'agit d'une catégorie de classification non formelle qui regroupe, au niveau interspécifique, des individus ou des populations présentant des caractères similaires d'ordre morphologique, génétique et écologique (Anderson \& Cutler 1942, Harlan \& De Wet 1977). La capacité de transmettre ces caractères aux générations suivantes, comme produit de la sélection humaine et naturelle est également prise en compte (Hernández \& Alanís 1970) et on l'associe généralement aux systèmes agricoles traditionnels (Camacho et al. 2006).

21 La première recherche au niveau national sur le maïs mexicain a été menée dans les années 1940 par Oficina de Estudios Especiales (Bureau des études spéciales), dans le cadre de la collaboration établie entre le ministère de l'Agriculture et la Fondation Rockefeller. L'un des objectifs proposés était d'accroître la production de cultures de base, de cataloguer et de préserver les sources de matériel génétique avant leur remplacement éventuel par l'introduction d'hybrides, comme cela s'était déjà produit aux États-Unis (Ortega et al. 1991, Fenzi 2017). Cette recherche a produit l'ouvrage Razas de maíz de México (Wellhausen et al. 1951), base de la connaissance des principaux types de maïs, où 27 races ont été signalées. Cette étude fut ensuite menée dans d'autres pays d'Amérique latine.

Grâce aux travaux développés dans des régions moins explorées (Hernández \& Alanís 1970, Benz 1986) ou pour répondre aux besoins nationaux d'amélioration dans les zones marginales (Ortega et al. 1991), de nouvelles races ont été ajoutées à celles déjà signalées par Wellhausen et al. (1951). Dans les compilations et les études ultérieures sur la diversité des races de maïs mexicains, entre 41 (Ortega et al.1991) et 59 races (Sánchez et al. 2000) sont reconnues. Une étude récente, résultat d'un effort national mené par de nombreuses institutions et chercheurs du pays, fait état de 64 races de maïs (CONABIO 2011, Comisión nacional para el conocimiento y uso de la biodiversidad), soit 30 \% des races recensées en Amérique latine (Goodman \& Mck, Bird 1977). 


\section{Races de maïs au Mexique}

Le nombre et la diversité des populations de maïs originaires du Mexique sont très importants. Elles présentent un continuum en termes de variation morphologique, géographique et génétique (Doebley et al. 1985, Kuleshov 1930, Pressoir \& Berthaud 2004, Wellhausen et al. 1951). La catégorie de race recouvre des fragments de ce continuum et, d'une certaine manière, permet de le comprendre et de le décrire. Chaque race peut inclure des populations présentant des variations concernant les adaptations, le cycle productif, les couleurs et les textures du grain. Fréquemment les populations de maïs cultivées par les agriculteurs peuvent rassembler des caractéristiques de plus d'une race (Ortega 2003). Celles-ci, à leur tour, peuvent être classées en sous-groupes ou complexes raciaux en fonction de leur zone de répartition, de leurs similitudes morphologiques et génétiques mais également en prenant en compte un probable processus évolutif partagé (Goodman \& McK. Bird 1977, Sánchez et al. 2000).

Grâce à l'analyse combinée des caractères morphologiques et des marqueurs génétiques des isoenzymes, sept grands groupes se distinguent: Cónico, Sierra de Chihuahua, Chapalote, Ocho Hileras, Maduración tardía, Maduración temprana et Dentados tropicales. Ils correspondent dans une certaine mesure aux régions biogéographiques du pays et seront utilisés dans le présent travail afin de regrouper et d'organiser les races de maïs reconnues au Mexique (Tableau 2. Figure 3).

Tableau 2 : Races de maïs au Mexique, caractéristiques principales et régions dans lesquelles elles sont cultivées

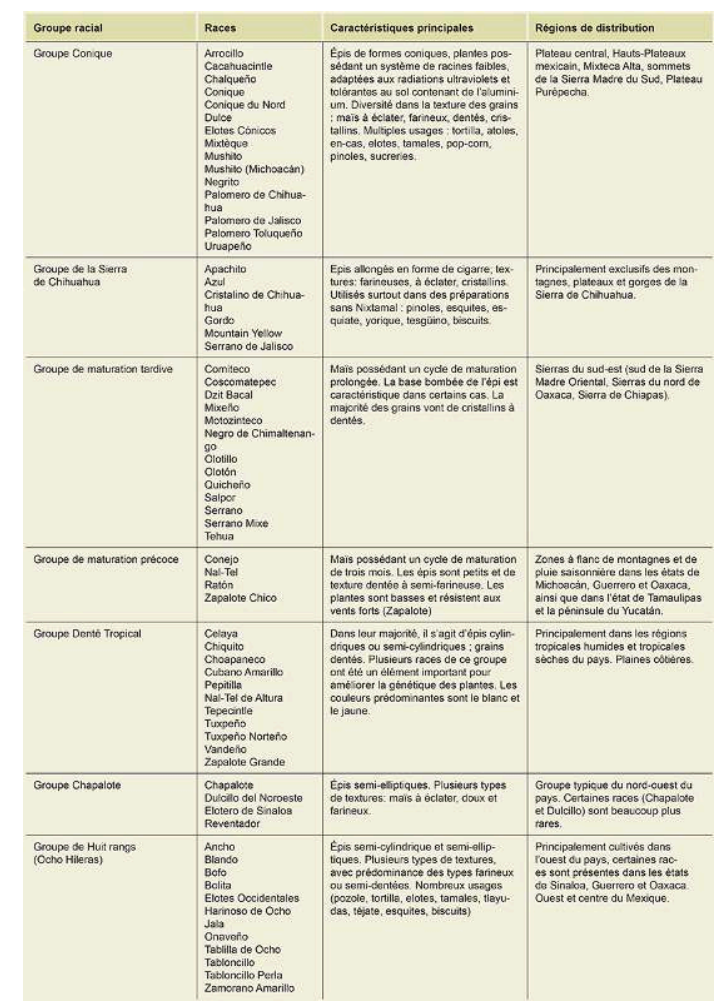

D'après Mota 2016, Ortega 2003, Sánchez et al. 2000 
Figure 3 : Quelques races de maïs au Mexique

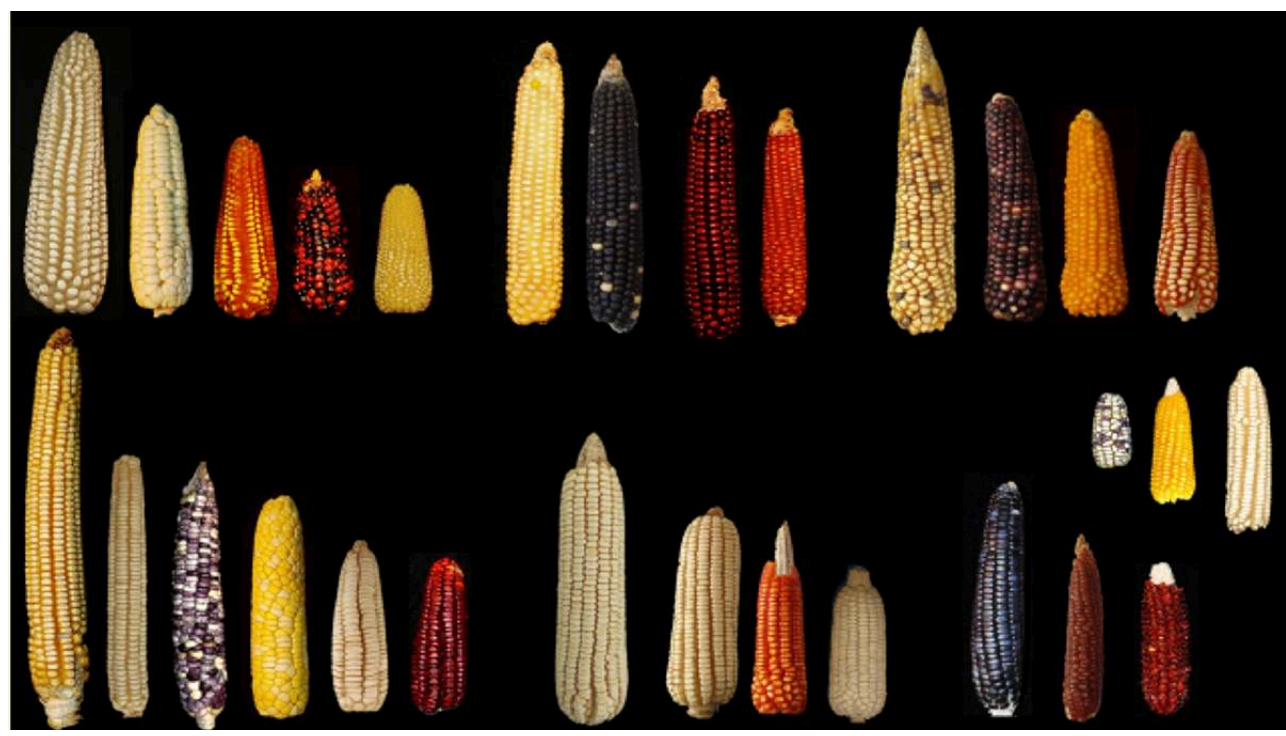

Partie supérieure : Groupe Cónico (Chalqueño, Cacahuacintle, Cónico, Elotes cónicos, Arrocillo). Groupe Sierra de Chihuahua (Cristalino de Chihuahua, Azul, variante Roja, Apachito). Groupe Maduración tardía (Comiteco, Olotón - azul et amarillo - , Motozinteco)

Partie inférieure : Groupe Ocho hileras (Jala, Tabloncillo, Perla, Bofo, Blando, Ancho, Bolita). Groupe Dentados tropicales (Tuxpeño, Vandeño, Tepecintle, Zapalote grande). Groupe Chapalote (Elotero de Sinaloa, Chapalote, Dulcillo del Noroeste)

Partie du milieu: Groupe Tropicales precoces (Zapalote chico, Nal-tel, Ratón)

Photographie D. Villanueva et C. Mota.

Les maïs indigènes se cultivent presque dans toutes les régions où l'agriculture mexicaine est pratiquée. Chaque région a développé une certaine diversité correspondant à ces groupes raciaux. On retrouve ainsi dans la Sierra de Chihuahua des races avec un épi allongé et en forme de cigare alors que, dans les montagnes du sud et sud-est du pays, les types de maïs présents possèdent un épi à la base gonflée et des grains cristallins qui sont propres aux variétés de maturation tardive. Dans la cordillère néo-volcanique, c'est le groupe Cónico qui est le plus représenté. Tandis que les races de maïs Ocho hileras prédominent dans l'ouest du pays et le groupe Chapalote dans le nordest. Les races telles que Tuxpeño, Tuxpeño Norteño ou Celaya du groupe Dentados tropicales, grâce à leurs caractéristiques agronomiques appréciables, sont largement répandues et utilisées pour l'amélioration des variétés, en particulier dans les régions tropicales humides et sèches du pays. Les races Maduración temprana ont été sélectionnées pour leur adaptation à des conditions environnementales variables, comme stratégie pour éviter les périodes de sécheresse. Elles ont été également sélectionnées afin d'obtenir une récolte rapidement en attendant que les races à cycle long soient prêtes à être consommées (Wellhausen et al. 1951). Aujourd'hui, ces matériaux deviennent particulièrement pertinents face au changement climatique.

\section{Importance agronomique et culturelle de la diversité du maïs au Mexique}

On considère que la diversité de forme d'une espèce domestiquée est produite par sa diversité génétique intrinsèque (plus importante encore chez ses ancêtres sauvages), par l'environnement dans lequel elle est cultivée et adaptée mais également par la 
gestion et l'utilisation faite par la population qui s'occupe de sa conservation (Leclerc \& d'Eeckenbrugge 2012, Perales et al. 2005, Castillo 2004). Chacun de ces éléments soustend, exprime et combine différents processus : la nature biologique de la plante, tout ce qui est relatif à la mutation, la migration, l'hybridation, la dérive génétique, le flux de gènes (Sánchez 2011, Pressoir \& Berthaud 2004). La diversité d'une espèce s'appuie également sur son adaptation environnementale et sa résistance aux facteurs biotiques et abiotiques (Sánchez 2011, Vavilov 1994) ainsi qu'aux conditions socio-économiques déterminées par les aspects du marché, les usages et le flux des semences (Bonfil 2012, Eakin et al. 2014, Louette et al. 1997).

\section{Diversité génétique}

Parmi toutes les espèces animales ou végétales, le maïs est une de celles qui présente une des plus grandes diversités génétiques (Tenaillon et al. 2001); bien qu'au cours du processus de domestication, il y ait eu une diminution - bottleneck - de la diversité génétique due à la sélection d'un groupe réduit de plantes présentant des caractéristiques différentes de celles des sauvages (Doebley 2004). Dans le cas du maïs, et plus particulièrement du maïs indigène, un pourcentage élevé de la diversité des nucléotides est conservé (83\%), ce qui fait que la différenciation génétique entre les variétés est mineure (Hufford et al. 2012). Cette diversité est maintenue au sein des différentes populations ou races mais elle est encore supérieure en ce qui concerne le maïs indigène du Mexique par rapport à d'autres régions du monde (Doebley et al. 1985, Reif et al. 2006, Vigoroux et al. 2008).

\section{Environnement}

$\mathrm{Du}$ fait de sa situation géographique et orographique, il serait possible de dire que tous les climats du monde sont représentés au Mexique: deux tiers de son territoire se situent au-dessus de $800 \mathrm{~m}$ d'altitude et présentent une orographie accidentée et des conditions édaphiques diverses (Castillo 2004). Le maïs est cultivé depuis le niveau de la mer jusqu'à $3400 \mathrm{~m}$. Il prospère depuis les régions semi-arides avec moins de $300 \mathrm{~mm}$ de pluie annuelle jusqu'aux zones tropicales qui reçoivent environ $4000 \mathrm{~mm}$ de précipitations annuelles. Les conditions d'altitude, associées aux variations climatiques et orographiques, constituent un facteur de différenciation génétique et d'adaptation du maïs indigène au Mexique. On parle alors de maïs des zones hautes ou tempérées, de maïs des zones intermédiaires et de maïs des basses terres (Ortega 2003, Vigouroux et al. 2008). Il en va de même en ce qui concerne les variations de latitudes (Arteaga et al. 2015) qui ont été reconnues déterminantes lors de l'introduction et l'adaptation du maïs, dans les zones du nord du Mexique ou des États-Unis caractérisées par des photopériodes plus importantes.

La diversité du maïs indigène au Mexique s'est adaptée à la saisonnalité marquée des pluies qui caractérise le pays; la distinction entre saison sèche et pluvieuse est plus importante que celle existant entre les saisons printemps-été-automne-hiver des latitudes plus septentrionales. Il existe, pendant la saison des pluies, qui se concentrent entre avril et septembre, une période de sécheresse ou de canicule qui correspond au moment de la floraison du maïs. Certaines races ont été sélectionnées afin d'obtenir une plus courte période de maturation (trois mois), qui permet d'échapper à cette période de sécheresse (par ex. la race Nal-Tel dans la péninsule du Yucatán). Leur 
culture fait partie d'une stratégie paysanne permettant d'obtenir des graines pour des usages variés (épis jeunes, galette, boisson de maïs jeune ${ }^{1}$ ) alors que les formes plus tardives sont productives seulement après la période de sécheresse (Dzib \& Arias 2011, Wellhausen et al. 1951).

Les sols volcaniques des hautes vallées du centre du pays ont tendance à présenter une forte teneur en aluminium, condition à laquelle se sont adaptés les maïs des races Cónico, Chalqueño, Purépecha et Serrano de Jalisco. Dans les zones tropicales pluvieuses, les sols présentent un déficit en phosphore qui convient à un grand éventail de races telles que les Tepecintle, Olotillo et Tuxpeño. Des associations avec les mycorhizes, qui favorisent l'absorption de ce minéral, ont été observées, en particulier pour certaines formes de ces races au grain bleu foncé (Sangabriel et al. 2014).

Dans les zones montagneuses où les précipitations et l'humidité relative sont élevées, les populations de maïs (par ex. la race Olotón dans la Sierra de Oaxaca) développent de grandes racines adventives qui, en plus de soutenir et de supporter la plante sur les terrains aux pentes raides, sécrètent des exsudats dans lesquels se développent des bactéries fixatrices d'azote et des substances à activité antibiotique qui, respectivement, fournissent cet élément à la plante et empêchent les problèmes liés aux maladies fongiques (Vega \& Ferrera 1996).

Dans les régions de fortes pluies, les agriculteurs ont sélectionné des variétés dont les épis étaient totalement recouverts par une couche très épaisse de spathes, laquelle protège de la pluie dans les champs et des attaques des insectes dans les sites de stockage, les attaques du grain par les insectes. Un épi présentant des spathes plus longues est, en outre, utile pour l'emballage des tamales (aliment typique à base de pâte de maïs fourrée de divers ingrédients et cuit à la vapeur); dans certaines régions les spathes de maïs s'utilisent pour fabriquer des objets d'artisanat (Figure 4); dans d'autres, la commercialisation de ce sous-produit représente donc une source de revenus importante pour les familles et les communautés et en même temps participe à la conservation des variétés criollas spécifiques pour ces usages des spathes (King 2007).

Figure 4 : Artisanat élaboré à partir des spathes de maïs (totomoxtle)

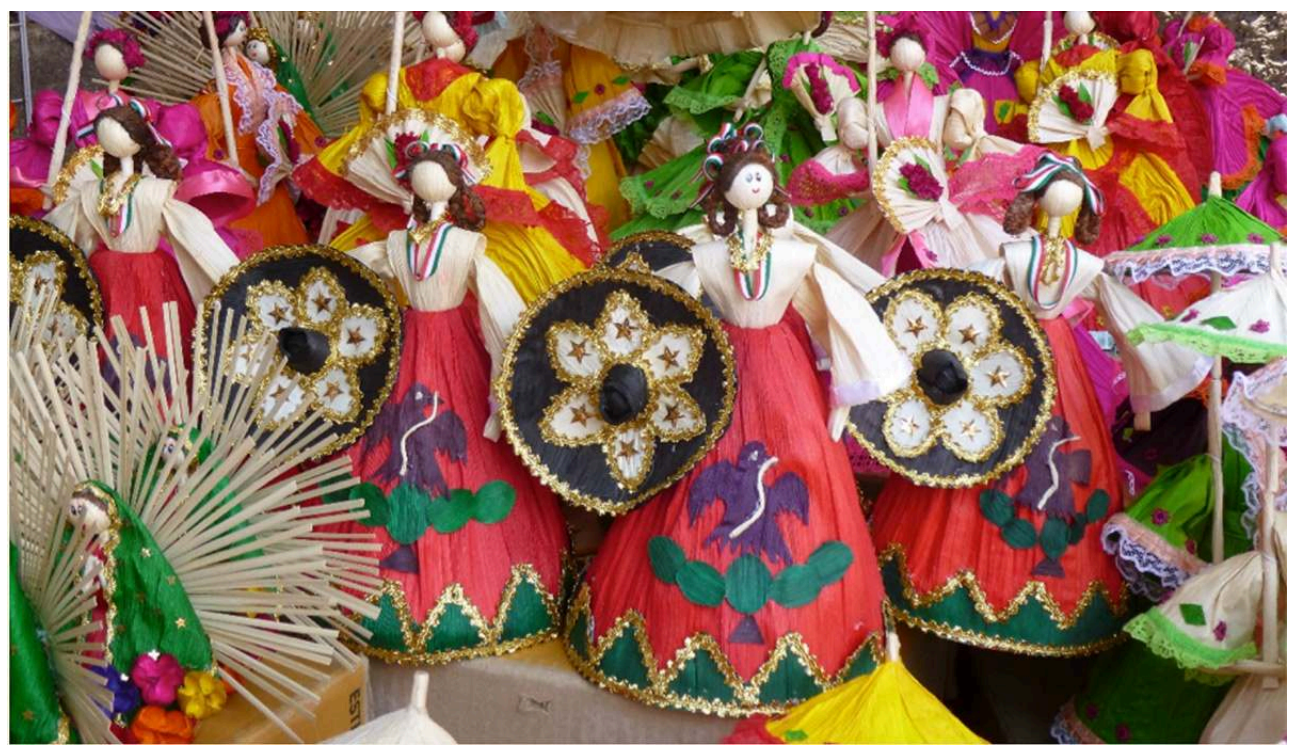

Photo: C. Mota 


\section{Société}

\section{Gestion des semences par les agriculteurs} est particulièrement notable au Mexique où les agriculteurs sèment de grandes quantités de populations à pollinisation libre sur des parcelles de taille variable et entre lesquelles des échanges de gènes ont lieu de manière naturelle. Le système reproductif du maïs rend possible ces échanges, grâce à l'action du pollen, entre populations et à l'intérieur d'une même population. En d'autres termes, un agriculteur peut semer différentes variétés ou types de maïs dans un champ ou dans plusieurs appartenant à la même localité. De plus, ce flux génétique est facilité par la gestion et l'échange des semences effectuées par les agriculteurs lorsqu'ils essayent de cultiver de nouveaux types de maïs sur un même site ou bien dans des régions voisines ou distantes (Hérnandez 1985, Louette et al. 1997)

Le système millénaire de conservation et de reproduction des semences a permis la préservation et l'évolution de la diversité du maïs. Il se base sur la sélection année après année de la semence provenant des matériels génétiques originels mais aussi des variétés dérivées d'amélioration formelle. À partir de ces dernières, on obtient une semence qui postérieurement en se mélangeant avec les maïs indigènes et ceux sélectionnés durant plusieurs générations créent une variété appelée «hybrides créolisés » ou générations avancées d'hybrides (Ortega 2003). Les agriculteurs cultivent à la fois ces générations avancées d'hybrides tout en continuant de semer des variétés originelles possédant de meilleurs attributs pour la consommation et l'alimentation d'usage local (Bellon 1991, Ortega 2003). Cette gestion tend, en outre, à baisser le prix des semences locales ou ceux des hybrides créolisés et favorise une plus grande stabilité de production les années de mauvaise récolte que ce que permettent les maïs hybrides commerciaux (Mota 2015).

\section{Les systèmes agricoles}

Les systèmes agricoles sont différents selon que l'on se trouve dans des zones situées au niveau de la mer ou à d'autres altitudes au Mexique. Dans les basses terres tropicales et en climat tropical sec, l'agriculture sur abattis-brûlis est mise en place depuis les temps préhispaniques. L'importance de ce procédé dépend des années de jachère, des terres disponibles et de la pression anthropique. Les systèmes mis en place dans les régions arides et semi-arides sont basés sur la conservation du sol et de l'eau, à l'aide de barrages au fond des ravins. Dans les zones tempérées, des maïs adaptés à des systèmes de culture particuliers existent, par exemple les metepantles ${ }^{2}$ où le maïs est semé entre les rangs d'agaves (Agave spp.) et cultivé sur des terrasses et celui des chinampas ${ }^{3}$ - qui fait partie des agrosystèmes mésoaméricains les plus productifs - et qui consiste en des terre-pleins de sédiments et de matières organiques provenant du fond des lacs et canaux au sud de la Vallée de Mexico.

36 À partir $\mathrm{du} \mathrm{xvI}^{\mathrm{e}}$ siècle, l'utilisation de la charrue a permis la mise en culture de nouvelles terres, notamment les riches vallées de la région du Bajío dans les États de Guanajuato, Jalisco et Michoacán ainsi que le plateau mexicain. De nouvelles races indigènes à haut rendement furent développées par les agriculteurs, telles que les Coniques $d u$ Nord ou celle de Celaya, qui ont ensuite été utilisées pour créer des 
semences améliorées (Wellhausen et al. 1951, Fenzi 2017). Dans ces régions, la Révolution verte a été fortement encouragée. Cette dernière s'appuyant sur l'utilisation d'hybrides d'origine commerciale, de fertilisants, de pesticides ainsi que sur la mécanisation. Elle a causé un important déplacement du matériel génétique présent dans les cultures antérieures.

\section{La milpa}

La culture traditionnelle du maïs au Mexique associe, dans certaines régions, cette plante à différents types de haricots (Phaseolus spp.; Vigna sp.) ainsi qu'aux courges (Cucurbita spp.) dans un système de polyculture appelé milpa (Figure 5). Cet agrosystème a permis également l'utilisation et la domestication d'autres espèces telles que les tomates (Solanum esculentum, Physalis sp.), les piments (Capsicum spp.) et d'autres légumes rassemblés sous le terme quelites ${ }^{4}$ (Amaranthus, Chenopodium, Crotolaria, Portulaca, Solanum etc.). D'autres plantes poussant de manière spontanée sont utilisées pour le fourrage. De même, dans certaines régions du Mexique, la partie interne du champignon Ustilago maydis, huitlacoche, qualifié de maladie grave du maïs sous d'autres latitudes, est consommée et même considérée comme un mets délicat surtout dans le centre du pays.

Figure 5 : Milpa dans les Altos de Chiapas

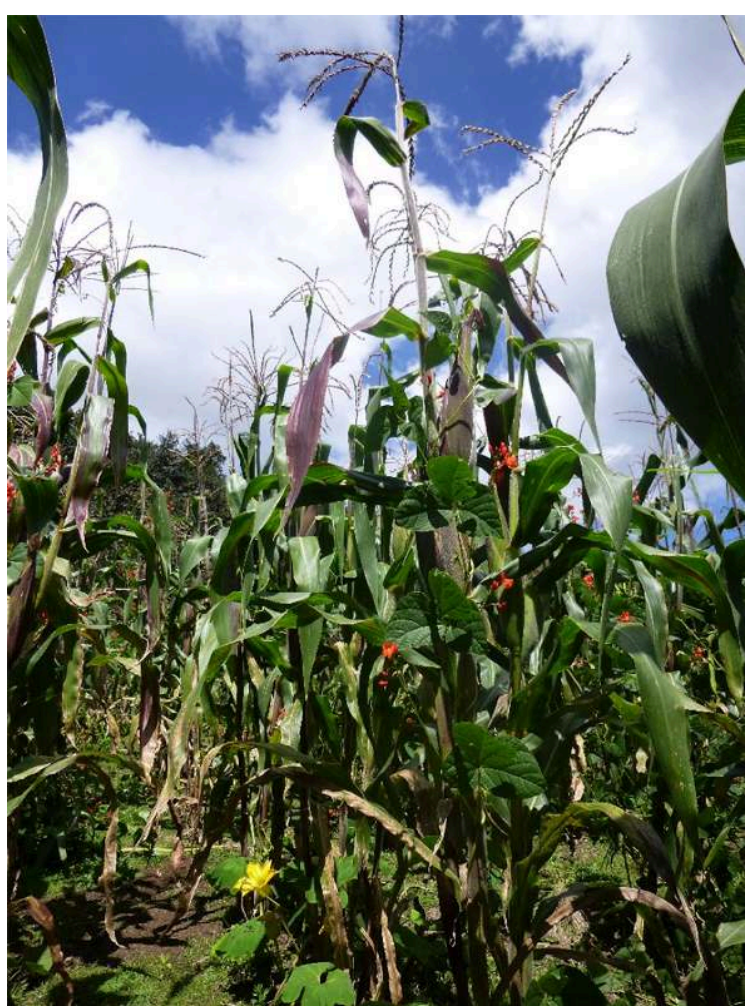

Photo: C. Mota Cruz

La milpa était probablement présente dans beaucoup plus de régions avant que la Révolution verte n'ait lieu au milieu du siècle dernier. Ce système est encore utilisé dans les zones de productions marginales, les régions montagneuses et dans plusieurs territoires concentrant des populations indiennes ou métisses, mais il a été pratiquement remplacé ou a même complètement disparu dans les zones irriguées ou 
jouissant d'un climat favorable. Cette réduction d'usage de la milpa est notamment due à des facteurs économiques, sociaux et politiques. Cette situation a cependant entraîné la perte de ressources génétiques, également perte d'un vaste ensemble de connaissances ainsi que l'appauvrissement du régime alimentaire, en remplaçant ou diminuant ces cultures et ces denrées, complémentaires aussi bien pour l'agrosystème que pour l'alimentation. Chaque milpa a des besoins différents en termes de croissance et de lumière selon les espèces cultivées. Les milpas occupent donc des niches écologiques distinctes, en termes d'optimisation de la lumière et de qualité du sol. Les fonctions des différentes espèces sont complémentaires : le maïs sert de soutien aux haricots qui comme toutes légumineuses fixent le nitrogène dans le sol alors que les courges, grâce à leurs larges feuilles couvrantes empêchent la pousse des mauvaises herbes. En ce qui concerne les apports nutritionnels, le maïs est la source principale d'énergie, le manque de protéines de ce dernier est pallié par les haricots et les courges, celles-ci étant également riches en acides gras. Les autres espèces, comme les quelites, les tomates et les piments couvrent les besoins en vitamines et minéraux.

\section{Diversité des usages alimentaires}

39 Au Mexique, la diversité des couleurs et des textures des grains de maïs permet de multiples usages et des préparations culinaires qui apportent des variations au régime alimentaire. On retrouve ainsi des maïs blancs, jaunes, bleus, pourpres et violets dans les tortillas, les tamales, les atoles, les pozoles, etc. mélangeant couleurs et saveurs. D'ailleurs, les grains du maïs s'utilisent dans ces différents états phénologiques grâce à la connaissance de la plante et aux techniques qui permettent de transformer et rendre digestes les préparations à base de maïs (Mota 2019). La cuisine mexicaine, à base de maïs, a bien évidemment su s'enrichir et multiplier les saveurs en associant les autres espèces présentes dans la milpa, notamment les nombreux piments, et en insérant des plantes, des animaux et autres produits venant d'ailleurs comme la canne à sucre, des fruits, des légumes, des épices, des condiments, etc.

$\mathrm{Au}$ Mexique, une même race de maïs peut présenter des couleurs et des textures différentes et, par conséquent, donner naissance à des usages alimentaires divers. Par exemple, la race Chalqueño, dite de Chalco, l'une des plus productives des hautes vallées du centre du pays, présente les variétés suivantes : «crème », couleur blanc crème, utilisée pour les tortillas; le Palomo blanc émaillé et de texture semi-farineuse, idéal pour les tamales et elotes; Azul à grains bleus foncés et semi-farineux pour les antojitos, les spécialités (quesadillas, sopes, gorditas); le maïs Xitocle appelé également «sang du Christ » de teinte allant du rose au rouge intense et de texture semi-farineuse pour la préparation du pinole, de confitures et de friandises; le "maïs jaune » semi-cristallin utilisé pour alimenter les volailles de basse-cour (Herrera et al. 2004, Ortega com. pers.) (Figure 6). Cette distinction de couleurs peut également être liée aux étapes de maturité comme cela a pu être observé avec la race Cónico des vallées centrales du pays: les grains blancs correspondent au maïs mûr, les jaunes à un stade intermédiaire et les bleus aux étapes précoces (Hernandez X. 1971). 
Figure 6 : Variation de la race Chalqueño. De gauche à droite : Crema, Palomo, Azul, Xitocle y Amarillo.

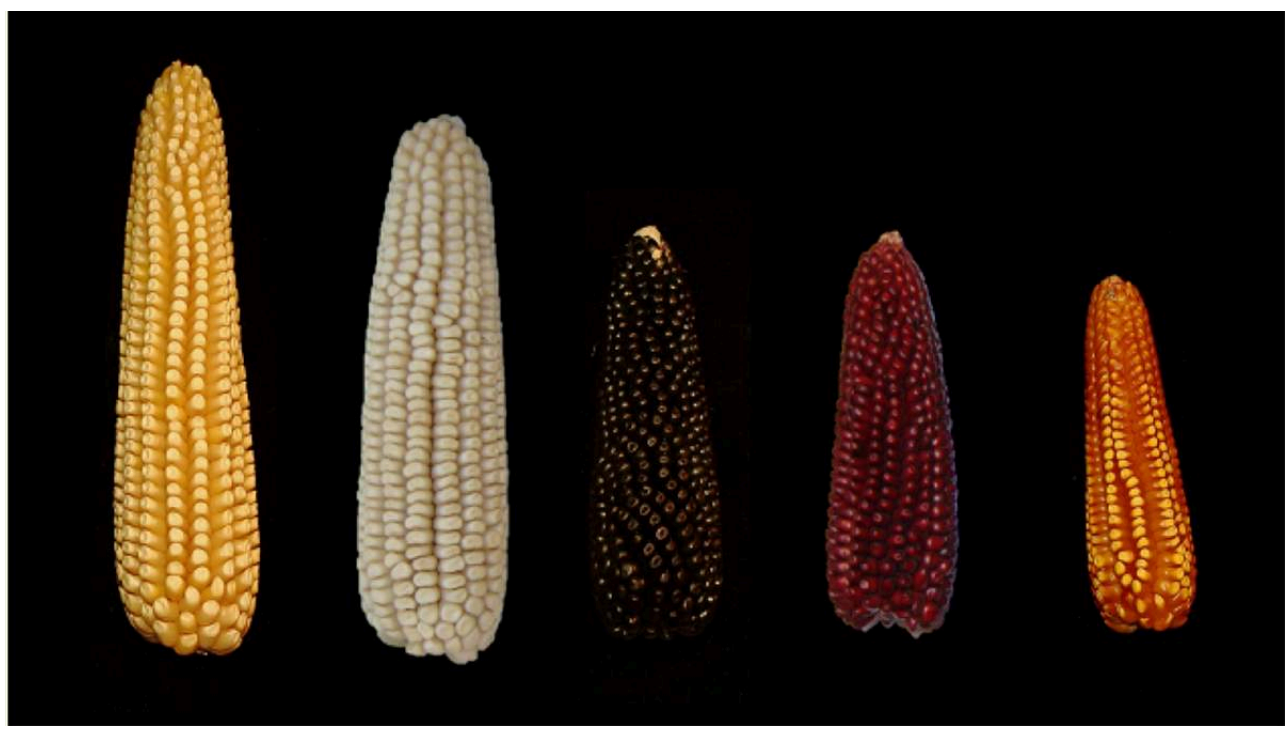

Photo: D. Villanueva et R. Ortega-Paczka

41 L'importante et fréquente consommation du maïs au Mexique s'explique par la large utilisation que l'on peut faire des différentes parties de la plante mais principalement de son grain à des stades de développement et de maturité divers. Les études en archéo-botanique suggèrent que le jus de la tige du maïs, à un stade de maturation précoce, était davantage consommé avant l'introduction de la canne à sucre (MacNeish $1967)^{5}$. La consommation de jeunes tiges de téosinte, qui sont également sucrées, a été considérée comme un motif possible de domestication du maïs (Smalley \& Blake 2003). La panicule est peu utilisée sauf pour quelques préparations (les tamales) lorsqu'il est encore frais et contient du pollen (Echeverría \& Arroyo 2000). La consommation de l'épi frais du maïs (elote) est importante et il existe des races spécialement sélectionnées pour cette utilisation (tel les Elotes Occidentales, Elotes Cónicos, Cacahuacintle) ${ }^{6}$.

Lorsque le grain se trouve dans une étape intermédiaire entre tendre et presque mûr, d'un aspect laiteux, parfois appelé camahua dans certaines régions, il sert de base à des préparations culinaires (tlaxcales ou gorditas) qui ne peuvent se faire qu'à ce degré de maturation et lui donnent une saveur et une odeur caractéristique. Le grain sec est également transformé et préparé de différentes manières pour élaborer des centaines de mets différents (Echeverria \& Arrolo 2000).

La consommation importante du maïs au Mexique à des fins alimentaires est due en grande partie aux multiples et intéressants processus technologiques qui sont utilisés lors de sa transformation pour le rendre digeste : il est, tour à tour, rôti, cuit, bouilli, grillé, fermenté, éclaté étant sec (pour le popcorn) ou humide (pour le pozole). Le processus de " nixtamalization " provenant du terme nahuatl nixtamal tient une grande place dans ce domaine. Celui-ci tire probablement son origine de la Mésoamérique et consiste à cuire le grain dans une solution alcaline (eau avec de la chaux ou de la cendre) (Katz et al. 1974). Ce processus a pour but d'éliminer le péricarpe du grain et faciliter son hydratation pour qu'il soit ensuite broyé et que l'on obtienne une pâte, appelé masa servant de base à un grand nombre de plats. Le produit principal de la masa est la tortilla qui restent la préparation à base de maïs la plus consommée au Mexique et au Guatemala. De plus, la nixtamalisation entraîne des bienfaits nutritionnels en 
intégrant du calcium dans le régime alimentaire et en favorisant l'équilibre des aminoacides qui facilite la biodisponibilité de la niacine dont le manque provoque la pellagre. D'autre part, ce processus permet d'augmenter la salubrité des aliments en éliminant de 70 à $80 \%$ des aflatoxines (Bressani 1990).

Les utilisations du maïs au Mexique se sont multipliées grâce à la nixtamalisation, plus de 600 préparations distinctes sont élaborées telles que tortillas, tamales, atoles, pozol et pozoles, tostadas, tlacoyos, gorditas, etc. (Echeverría \& Arroyo 2000).

Le maïs est présent dans tous les repas de la journée, principalement avec les tortillas mais, en fonction de la région, du moment de la journée, de l'occasion ou de la festivité, les plats diffèrent. Les tamales sont consommés généralement lors du petit-déjeuner ou du dîner, ils sont également préparés pour certaines fêtes récurrentes, célébrations familiales ou événements spéciaux comme les mariages. Pour cette seule préparation, 300 variantes ont été enregistrées (Pérez 2003). Elles peuvent être petites (de la taille d'une main) ou énormes comme le zacahuil mesurant plus de $50 \mathrm{~cm}$. Ce dernier est utilisé pour les festivités et mariages dans la région de la Huastecas.

Le pozole (Figure 7), une sorte de soupe faite à base de maïs éclaté lors de sa cuisson dans l'eau, est normalement consommé lors de festivités. Son usage s'est étendu audelà de l'État de Guerrero, d'où il est probablement originaire. Il est devenu un plat caractéristique des États de Jalisco et de Mexico, il est largement consommé dans la ville de Mexico et des variations de ce plat existent avec du maïs spécifique à Chihuahua, Sonora, Sinaloa.

Figure 7 : Pozole blanco, plat typique à base de maïs éclaté de la race Ancho. Guerrero, México

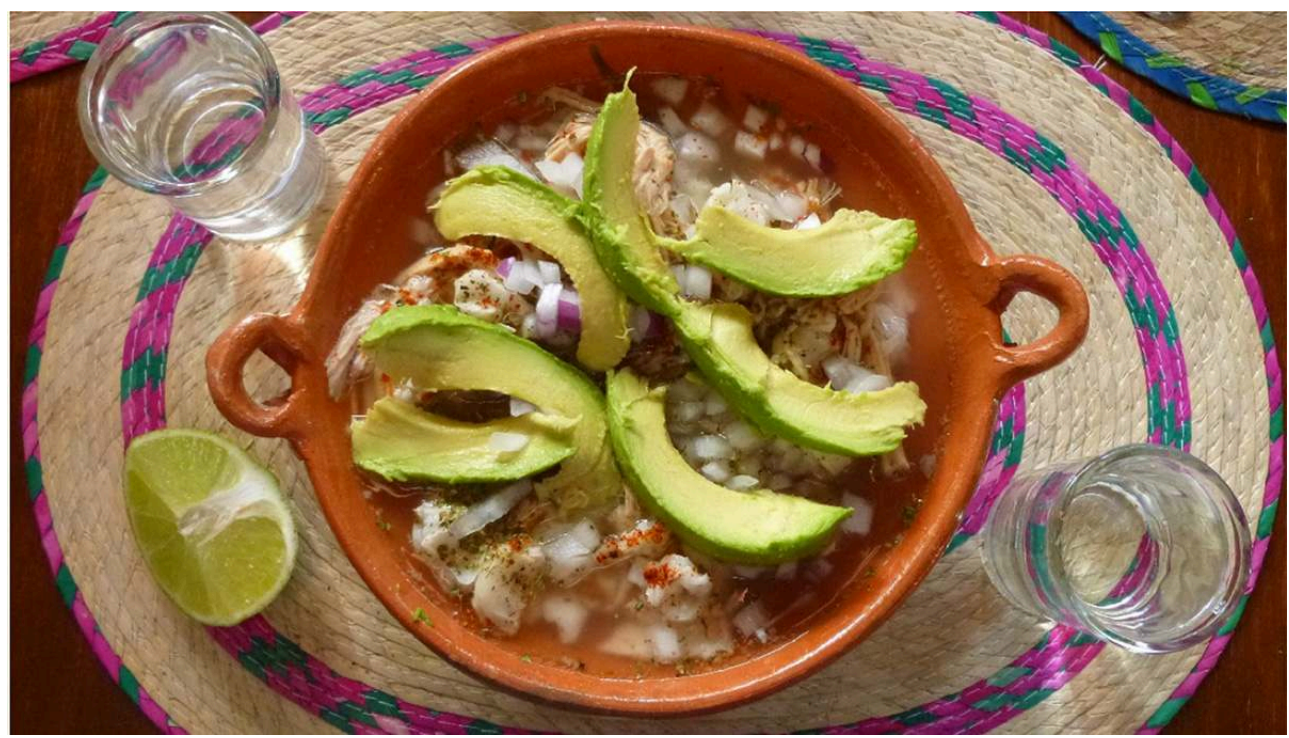

Photo: C. Mota

Il existe plusieurs versions de pozole se préparant avec des maïs Ancho, Cacahuacintle, Elotes Occidentales, Blando de Sonora et Gordo, ayant tous pour caractéristiques la capacité d'éclater lors de leur cuisson à l'eau.

Un grand nombre de boissons (froides, chaudes, fermentées, alcoolisées) sont préparées avec du maïs. Le mélange d'ingrédients comme le chocolat, des graines et des fruits tropicaux, des essences de fleurs et la pâte de maïs préparée spécialement pour cette 
occasion, crée de délicieuses boissons telles que le tejate, l'atole de chocolat ou le bupu de Oaxaca.

Dans le sud-est du Mexique, la consommation du pozol, une boisson à base de pâte de maïs nixtamalisé et de maïs éclaté est commune, notamment dans la péninsule du Yucatán ou dans les régions tropicales. Il peut être bu frais ou fermenté et aide à étancher la soif, à apaiser la faim et à se rafraîchir pendant les heures les plus chaudes de la journée. Les maïs blancs, jaunes et bleus des races Tuxpeño, Olotillo, Tepecintle, Dzit Bacal et Nal-Tel sont destinés à cet usage dans ces régions. Dans la Sierra de Los Tuxtlas, au sein de l'État de Veracruz, les variantes bleu foncé, noir et rouge sont préférées.

Dans le nord-ouest, notamment dans les communautés indigènes de la Sierra Madre occidentale, un grand nombre de préparations culinaires à base de maïs n'utilise pas le procédé de nixtamalisation: pinole, esquite, esquiliate, tesgüino. La préparation et la consommation de pinole (maïs grillé et moulu) dans ces régions est probablement la plus importante de tout le pays. Ici aussi, la consommation d'une bière traditionnelle (tesgüino) à base de maïs est importante dans les festivités, le travail collectif et comme boisson rituelle.

\section{Quelques aspects socio-économiques}

51 Compte tenu de ces apports alimentaires, le maïs est la culture la plus importante au point de vue social, économique et politique au Mexique. Certaines régions font un usage important d'intrants chimiques et de subventions gouvernementales, produisant ainsi d'importants volumes qui viennent approvisionner les grands marchés de consommation. Dans d'autres régions, la production se limite à la consommation propre même si une partie des excédents peut ensuite intégrer les marchés locaux ou régionaux. Dans les régions possédant un climat plus contraignant ou dans lesquelles les superficies cultivées sont plus limitées, le maïs est produit basiquement pour couvrir les besoins des agriculteurs (Eakin et al. 2014). Dans les territoires où l'arrosage repose seulement sur les pluies, la polyculture continue à être utilisée principalement pour l'autoconsommation, et cultiver le maïs permet, avant tout, d'assurer l'autonomie au moins pendant les mois suivant sa culture.

Pour la production de maïs, le schéma capitaliste propre à la Révolution verte a privilégié les semences hybrides commerciales qu'il faut donc impérativement racheter à chaque cycle de production. Cependant, malgré six décennies de promotion de ce système, on estime que seule $22 \%$ de la superficie nationale cultivée utilise le maïs hybride et cela dans les régions irriguées ou recevant suffisamment de pluies. Pour les $78 \%$ de champs restant, les agriculteurs continuent à semer leurs propres graines (Aquino et al. 2001). La majorité de celles-ci semblent être criollas, les hybrides créolisés représentant une proportion difficilement estimable. Au Mexique, l'adoption limitée des semences "améliorées" dans le pays, est due à plusieurs facteurs tels que: l'orographie complexe, le type de sol, le climat, le coût des semences mais aussi les préférences d'usage du maïs indigène et les questions culturelles. Ces circonstances permettent aux maïs locaux d'être encore assez souvent les plus appropriés et choisis. De plus, les semences améliorées selon les critères nord-américains fondés sur l'augmentation du rendement (Ortega-Paczka com. pers) ne rassemblent pas les qualités que les maïs criollos possèdent et qui permettent les usages alimentaires si variés existant au Mexique. 
La politique nationale concernant la production intensive industrielle de cette céréale, historiquement a d'abord bénéficié aux zones de production élevée disposant d'infrastructures, d'un système d'irrigation et de subventions. Dans les régions caractérisées par une agriculture familiale traditionnelle, les agriculteurs sont considérés comme des classes pauvres manquant de connaissances modernes. Ils reçoivent ainsi des aides monétaires pour l'achat de produits alimentaires importés. Ces aides ne sont pas destinées à soutenir leur activité agricole qui est pourtant un élément fondamental pour le maintien de la diversité de cultures mexicaines et pourrait être la clé pour le développement de ces zones rurales.

Dans quelques régions, certaines voisines des grands centres urbains tels que Mexico, les agriculteurs originaires des villages continuent à semer des maïs criollos des races Cacahuacintla, Chalqueño, Cónico, Palomero, Toluqueño et Elotes Cónicos. Cette activité génère des revenus grâce à la vente de produits de qualité (tortillas, maïs tendre) appréciés aussi bien sur le marché de consommation que représente Mexico que pour l'autoconsommation. Mais on peut également considérer cette activité comme une forme de préservation et de défense du territoire face à la croissante urbanisation (San Vicente \& Mota 2018).

\section{Commentaire final}

Si le Mexique est encore riche de toutes ces variétés de maïs, on le doit bien aux agriculteurs, à leur famille et à leur communauté, qui ont joué un rôle fondamental hier comme aujourd'hui pour générer et conserver cette diversité, en la considérant comme un bien commun. Leur système ouvert et dynamique de gestion des semences a permis de s'adapter aux multiples climats et reliefs du pays. Cette diversité a engendré une culture riche qui s'exprime depuis les civilisations précolombiennes jusqu'à aujourd'hui à travers des rites, des légendes, des danses, des manifestations culturelles, cosmogoniques et religieuses. Toutes ces expressions soulignent le caractère vital, alimentaire et culturel de cette plante que l'on retrouve à travers les nombreuses préparations et manières de la consommer cette céréale et qui a valu aux Mexicains, comme l'a remarqué Guillermo Bonfil Batalla (2012), le surnom de « peuple du maïs ».

\section{BIBLIOGRAPHIE}

Anderson E. 1946 - Maize in Mexico, a preliminary survey. Annals of Missouri Botanical Garden 33 : 147-247.

Anderson E. \& Cutler H.C. 1942 - Races of Zea mays I. Their recognition and classification. Annals of Missouri Botanical Garden 29 :69-88.

Aquino P., Carrion F., Calvo R. \& Flores D. 2001 - Selected maize statistics. In : Pingali P.L. (Ed.). CIMMYT 1999-2000 World Maize Facts and Trends. Mexico, D.F. CIMMYT : 45-58. 
Arteaga M.C. A. Moreno L., A. Mastreta Y., A. Vázquez L., A. Breña O, A. Moreno E., L. Eguiarte, D. Piñero 2015 - Genomic variation in recently collected maize landraces from Mexico. Genomics Data $7: 38-45$.

Beadle G.W. 1972 - The mystery of maize. Field Museum of Natural History Bulletin 43 :2-11.

Bellon M.R. 1991 - The ethnoecology of maize variety management: a case study from Mexico. Human Ecology 9(3) : 389-418.

Benz B.F. 1986 - Taxonomy and evolution of Mexican maize. Ph. D. Diss. Madison. University of Wisconsin, $433 \mathrm{p}$.

Benz B.F. 2001 - Archaelogical evidence of teosinte domestication from Guila Naquitz, Oaxaca. PNAS 98 (4) : 2104-2106.

Berthaud J., Savidan Y., Barré M. \& Leblanc O. 1997 - Tripsacum. In : Fucillo D., Sears L. \& Stapleton P. (Ed.), Biodiversity in Trust. Cambridge, UK. Cambridge University Press : 227-233. Bonfil G. 2012 - El maíz, fundamento de la cultura popular mexicana. México, D. F. CONACULTA, 114 p. Bressani R. 1990 - Chemistry, technology, and nutritive value of maize tortillas. Foods Reviews International 6 (2) : 225-264.

Camacho V., T.C., Maxted N., Scholten M. \& Ford-Lloyd B. 2006 - Defining and identifying crop landraces. Plant Genetic Resources 3 (3) : 373-384.

Castillo G., F. 2004 - Contribuciones de los recursos fitogenéticos a la genotécnia. In : Preciado O., R.E. \& Ríos S.A. (Ed.), Simposium Aportaciones de la Genotecnia a la Agricultura. Toluca, México. UAEM : $10-35$.

Chávez E. 1913 - Cultivo del maíz. Boletín No. 74 de la Estación Central Agrícola. México, D. F. Secretaría de Fomento-Dirección General de Agricultura.

Clayton W.D. 1973 - The awnless genera of Andropogoneae. Studies in Gramineae XXXIII. Kew Bulletin 28 (1):49-57.

CONABIO 2011 - Recopilación, generación, actualización y análisis de información acerca de la diversidad genética de maíces y sus parientes silvestres en México. México, D. F. http:// www.biodiversidad.gob.mx/genes/proyectoMaices.html Doebley J.F. 2004 - The genetics of maize evolution. Annual Review of Genetics 38 : 37-59.

Doebley J.F., Goodman M.M. \& Stuber C.W. 1985 - Isozyme variation in the races of maize from Mexico. American Journal of Botany 72 (5) : 629-639.

Dzib L.A. \& Arias L.M. 2011 - El cultivo y consumo de maíces precoces en Yucatán. Chapingo, México. UACh, $13 \mathrm{p}$.

Eakin H., Perales H., Appendini K. \& Sweeney S. 2014 - Selling maize in Mexico: the persistence of peasant farming in an era of global markets. Development and Change 45 (1) :133-155.

Echeverría M.E. \& Arroyo L.E. 2000 - Recetario del maíz. México, D. F. CONACULTA, 441 p.

Ellstrand N.C., Garner L.C., Hedge S., Guadugnolo R. \& Blancas L. 2007 - Spontaneous hybridization between maize and teosinte. Journal of Heredity 98 (2) :183-187.

Eubanks M.W. 2006 - Contributions of Tripsacum to maize diversity. In : Motley T.J, Zerega N. \& Cross H. (Ed.), Darwin's Harvest. New approaches to the origins, evolution, and conservation of crops. $\mathrm{N}$. Y., Columbia University Press : 91-117. 
Eubanks M.W., Xu J. \& Shar,a-Shivappa R.R. 2012 - High sugar Eastern gamagrass (Tripsacum dactyloides L.) cultivars as potential biofuel feedstock. Maydica 58 : 60-66.

FAOSTAT 2018 - Food and Agricultural commodities production/Commodities by regions/World/2018/ Quantity http://www.fao.org/faostat/en/\#data/QC/visualize. Consultado en junio de 2018.

Fenzi M. 2017 - "Provincialiser" la Révolution verte : savoirs, politiques et pratiques de la conservation de la biodiversité cultivée (1943-2015). Thèse doctorale. Centre Alexandre Koyré, École des Hautes Études en Sciences Sociales. Paris.

Galinat W.C. 1963 - Form and function of plant structures in the American Maydeae and their significance for breeding. Economic Botany 17 : 51-59.

Goodman M.M. \& McK. Bird R. 1977 - The races of maize IV: Tentative grouping of 219 Latin American races. Economic Botany 31 : 204-221.

Harlan J.R. \& De Wet J.M.J. 1971 - Toward a rational classification of cultivated plants. Taxon 20 (4) :509-517.

Hernández F. 1942 - Historia de las Plantas de la Nueva España. Instituto de Biología. http:// www.ibiologia.unam.mx/plantasnuevaespana/index.html

Hernández X., E. 1971 - Exploración etnobotánica y su metodología. Chapingo, México. CP.

Hernández X., E. 1985 - Maize and man in the Greater Southwest. Economic Botany 39 (4):416-430.

Hernández X., E. \& Alanís G. 1970 - Estudio morfológico de cinco razas de maíz de la Sierra Madre Occidental de México: Implicaciones filogenéticos y fitogeográficas. Agrociencia 5 (1) :3-30.

Herrera C., B.E., Castillo-González F., Sánchez-González J.J., Hernández-Casillas J.M. \& Goodman M.M. 2004 - Diversidad del maíz Chalqueño. Agrociencia 38 (2) :191-206.

Hufford M.B. et al. 2012 - Comparative population genomics of maize domestication and improvement. Nature Genetics 44 (7) : 808-813.

Humbold A. 1985 - Ensayo político sobre el Reino de la Nueva España. Miguel Ángel Porrúa, México, D. F.

Iltis H.H. \& Doebley J.F. 1980 - Taxonomy of Zea (Gramineae). II. Subspecific categories in the Zea mays complex and generic synopsis. American Journal of Botany 67 (6) :994-1004.

Kato T.A., Mapes C., Mera L.M., Serratos J.A. \& Bye R.A. 2009 - Origen y diversificación del maíz: una revisión analítica. México, D.F. UNAM-CONABIO. 115 p.

Katz S.H., Hediger M.L. \& Valleroy L.A. 1974 - Traditional processing techniques in the New World. Science 184 (4138) : 756-773.

King A. 2007 - Trade and Totomoxtle: Livelihood strategies in the Totonacan region of Veracruz, Mexico. Agriculture and Human Values 24 (1) :29-40.

Kuleshov N.N. 1930 - Maices de México, Guatemala, Cuba, Panamá y Colombia. In : Bukasov N.S. Las Plantas Cultivadas de México, Guatemala y Colombia. Costa Rica, CATIE : 40-53.

Leclerc C. \& d'Eckenbrugge G.C. 2012 - Social organization of crop genetic diversity. The G x E x S interaction model. Diversity $4: 1-32$.

Levy T.S., Avila A., Cuevas L., Chávez A., Avila M.A. \& Fernández C. 2003 - El subsidio a la tortilla en México: ¿un programa nutricional o económico? Archivos Latinoamericanos de Nutrición 53 (1) : 5-13. 
Limón E. 1945 - Informe de trabajos realizados en el Campo Agrícola Experimental de León, Guanajuato. México, D. F. Secretaría de Agricultura y Fomento, 68 p.

Louette D., Charrier A. \& Berthaud J. 1997 - In situ conservation of maize in Mexico: Genetic diversity and maize seed management in a traditional community. Economic Botany 51 (1) : 20-38.

MacNeish R.S. 1967 - A summary of the subsistence. In : Byers S. (Ed.), Environment and subsistence. I. The Prehistory of the Tehuacan Valley. Austin. University of Texas Press : 290-309.

Matsuoka Y., Vigouroux Y, Goodman M.M., Sánchez G., J.J., Buckler E. \& Doebley J.F. 2002 - A single domestication for maize shown by multilocus microsatellite genotyping. PNAS 99 (6) : 6080-6084.

Mera L.M. 2009 - Aspectos socioeconómicos y culturales. In : Kato T.A., Mapes C., Mera L.M., Serratos J.A. \& Bye R.A. (Ed.) Origen y diversificación del maíz: una revisión analítica. México. UNAMCONABIO : 33-41.

Mota C., C. 2015 - Selección de maíces nativos en campo por agricultores de la Cuenca Media del Grijalva, Chiapas. Sembradores 12 : 4-5.

Mota C., C. 2016 - Maíces nativos de México. In : Castillo G. (ed.), El maíz: nuestro rostro, nuestro corazón. Fundación Herdez : 59-69.

Mota C., C. 2019 - Diversidad de maíces nativos y aspectos relacionados a sus usos alimenticios. In : González M., M. (Ed.), Nuestra cultura alimentaria del maíz, diversidad de saberes y prácticas. Escuela Nacional de Trabajo Social, Universidad Nacional Autónoma de México : 67-86.

Ortega P., R. 2003 - La diversidad del maíz en México. In : Esteva G. \& Marielle C. (Ed.), Sin maíz no hay país. México D.F. CONACULTA : 123-154.

Ortega P., R., Sánchez G., J.J., Castillo G., F. \& Hernández C. J.M. 1991 - Estado actual de los estudios sobre maíces nativos en México. In : Ortega R. et al. (Ed.) Avances en el Estudio de los Recursos Fitogenéticos de México. Chapingo, México. SOMEFI : 161-185.

Perales H.R., Benz B.F. \& Brush S.B. 2005 - Maize diversity and ethnolinguistic diversity in Chiapas, Mexico. PNAS 102 (3) : 949-954.

Pérez San Vicente G. 2003 - Repertorio de tamales. México, D. F. CONACULTA, 262 p.

Piperno D.R., Ranere A.J., Holst I., Iriarte J. \& Dickau R. 2009 - Starch grain and phytolith evidence for early ninth millenium B.P. maize from the Central Balsas River Valley, Mexico. PNAS (13) : 5019-5024.

Polanco A. \& Flores T. 2008 - Bases para una política I\&D e innovación de la cadena de valor del maíz. México, D. F. Foro Consultivo Científico y Teconológico, A. C., 244 p.

Pressoir G. \& Berthaud J. 2004 - Population structure and strong divergent selection shape phenotypic diversification in maize landraces. Heredity $92:$ 95-101.

Reif J.C., Warburton M.L., Xia X.C., Hoisington D.A., Crossa J., Taba S., Muminovic J., Bohn M., Frisch M. \& Melchinger A.E. 2006 - Grouping of accessions of Mexican races of maize revisited with SSR markers. Teorethical and Applied Genetics $113: 177-185$.

Retes R.F. 2010 - Demanda de tortilla de maíz en México, 1996-2008. Tesis de Doctorado. Montecillo, México. CP, 159 p.

Rivera R. D.M., J.J. Sánchez G., L. De la Cruz L., F. Santacruz R. \& J.A. Ruíz C. 2019 - Morphological and climatic variability of teosinte (Zea spp.) and relationships among taxa. Systematic Botany 44 (1) : 41-51. 
Sahagún B. 1975. Historia general de las cosas de la Nueva España. México D. F. Porrua, 1061 p.

San Vicente T., A. \& C. Mota C. 2018 - El campo en la ciudad, la ciudad en el campo; maíces nativos en los pueblos originarios de Tlalpan, Ciudad de México. Fundación Semillas de Vida, A. C. México.

Sánchez J.J. 2011 - Diversidad del maíz y teocintle. México, D. F. CONABIO.

Sánchez J.J., Goodman M.M. \& Stuber C.W. 2000 - Isozymatic and morphological diversity in the Races of maize of México. Economic Botany. 54 (1) : 43-59.

Sánchez G., J.J., J. A. Ruíz C., G. Medina G., G. Ramírez O., L. De la Cruz L., J. B. Holland, R. Miranda M., G. E. García R. 2018 - Ecogeography of teosinte. PLoS ONE 13(2) : e0192676.

Sangabriel C., W., Negrete Y., S., Maldonado M., I.E. y Trejo A., D. 2014 - Native maize from Los Tuxtlas, Mexico, show varying mycorrhizal dependency for P uptake. Biol Fertil Soils 50 : 405-414. SIACON (Sistema de Información Agropecuaria de Consulta) 2014 - Base de datos. México, D. F. SAGARPA.

SIAP (Servicio de Información Agroalimentaria y Pesquera). 2008 - Situación actual y perspectivas del maíz en México 1996-2012. México, D. F. SAGARPA. 208 p.

Smalley J. \& Blake M. 2003 - Sweet beginnings: stalk sugar and the domestication of maize. Current Anthropology 44 (5) : 675-703.

Smith C. W., J. Betrán y E. C. A. Runge. 2004 - Corn: origin, history, technology, and production. John Wiley \&Sons. New Jersey.

Staller J.E., Tykot R.H. \& Benz B.F. (Ed.). 2006 - Histories of maize. San Diego CA. Academic Press. $678 \mathrm{p}$.

Taba S. 1995 - Maize germplasm: its spread, use, and strategies for conservation. In : Taba S. (Ed.), Maize genetic resources. México, D. F. CIMMYT.

Tenaillon M.I., Sawkins M.C., Long A.D., Gaut R.L., Doebley J.F. y Gaut B.S. 2001 - Patterns of DNA suquence polymorphism along chromosome 1 of maize. PNAS 98 (16) : 9161-9166.

Vavilov N.I. 1994 - Origin and geography of cultivated plants. Cambridge, UK. Cambridge University Press.

Vega S., M.L. \& Ferrera C., R. 1996 - Microorganismos del mucigel, rizoplano y rizósfera del maíz Olotón de la región Mixe, Oaxaca. In : Pérez M., J. \& Ferrera C., R. (Ed.), Avances de investigación, Microbiología de Suelos. Montecillo, México. CP, 41-49.

Vigouroux Y., Glaubitz J.C., Matsuoka Y., Goodman M.M., Sánchez G., J.J. \& Doebley J. 2008 Population structure and genetic diversity of new world maize races assessed by DNA microsatellites. American Journal of Botany 95 (10) : 1240-1253.

Wellhausen E.J., Roberts L.M., Hernández X., E. \& Mangelsdorf P.C. 1951 - Razas de maíz en México. OEE-SAG. Folleto técnico Núm. 55, 237 p.

Wilkes H.G. 2004 - Corn, strange and marvelous: But is a definitive origin known? In : Smith C.W., Betran J. \& Reinge E.C.A. (Ed.), Corn: Origin, History, Technology, and Production. N. Y. Wiley \& Sons : 3-63.

\section{ANNEXES}

Glossaire 
Bupu : boisson composée en partie d'atole de pâte de maïs servie chaude. On y ajoute une préparation mousseuse de cacao et de sirop de canne à laquelle on ajoute les corolles de la fleur de « Guiexachi » (Plumeria rubra) qui tout en aromatisant, donnent du volume et génèrent une mousse.

Esquiate : grains de maiis à maturité grillés, puis broyés dans de l'eau. Utilisés par les groupes Raramuri du nord-ouest du Mexique.

Esquites : nom donné dans plusieurs régions du Mexique aux grains de maïs grillés arrivés à maturité. Dans le centre du pays, le terme fait référence à des grains de maïs bouillis mijotés avec du saindoux, du piment et du chénopode (Dysphania ambrosioides). Pozol : boisson préparée avec des grains de maïs arrivés à maturité et cuits plus à plus haute température que pour les tortillas. Ils sont ensuite broyés pour former des boules de pâte qu'on laisse reposer afin d'atteindre divers degrés de fermentation. Ces dernières sont alors mélangées avec de l'eau et sont accompagnées, selon les régions, par du sirop de canne, du sucre, du piment, de la viande séchée, des fruits frais (mangue, prune, noix de coco), des cacahuètes pimentées... Consommée régulièrement dans les zones chaudes et tropicales du sud et du sud-est du Mexique.

Tejate : boisson rafraichissante préparée avec de la pâte de maïs, du cacao, des graines de sapotier (Pouteria sapota) et aromatisée avec une fleur endémique, connue sous le nom de « petite rose de cacao » (Quararibea funebris) dans les vallées centrales de l'État de Oaxaca.

Tesgüino : boisson alcoolisée préparée avec du maïs germiné, broyé, bouilli puis fermenté. Consommée par les groupes originaires du nord-ouest du Mexique.

Tlaxcale-gorditas : préparation ressemblant à une tortilla épaisse (environ $1 \mathrm{~cm}$ d'épaisseur) en forme de triangle, élaborée à partir de grains broyés de maïs ayant atteint un état de maturité intermédiaire, pâteux-laiteux (à mi-chemin entre le maïs tendre et le sec).

Tlayuda : galette de maïs de grande taille (approximativement $50 \mathrm{~cm}$ de diamètre) dont le degré de cuisson et la déshydratation est plus importante que pour une tortilla normale. Cela lui permet de garder une texture à la fois ferme et flexible permettant de l'utiliser pour une autre préparation du même nom. Usage commun dans les régions de l'État de Oaxaca.

Yorique : boisson de texture épaisse (comme l'atole) qui est consommée accompagnée de nopal. Utilisée par les groupes Raramuri du nord-ouest du Mexique.

\section{NOTES}

1. Elote, tortilla, atole nuevo, Elote et atole nuevo sont des préparations faites avec des grains non mùrs, encore laiteux et plus riches nutritionnellement que les grains mûrs. (note de la traductrice, FAS).

2. Metepantle, ou metepancle, terrain compris entre deux sillons d'Agave, (Note de FAS)

3. Chinampas, terrains de culture formés peu à peu sur les lagunes de la ville de Mexico. On y cultivait des légumes, des arbres fruitiers de petite taille, et aujourd'hui en plus des fleurs.(note de FAS)'

4. Quelite, nom de plusieurs herbacées sauvages et goûteuses dont on aime manger les feuilles, on les cueille jeunes pour qu'elles soient tendres, elles varient selon les régions (note FAS) 
5. En effet les tiges de maïs sont sucrées puisque, depuis environ 70 ans, on extrait du glucose des tiges de maïs et ce glucose est d'un revenu très minime, d'où son usage très répandu par l'agroindustrie occidentale. (note FAS)

6. Manger les grains jeunes encore laiteux est une pratique très répandue chez les consommateurs des céréales, type blés ou maïs, comme nous le voyons ici. En Égypte et Mésopotamie anciennes déjà on consommait les grains de blé ainsi et jusqu'á aujourd'hui les polentas d'Italie du nord et les gaudes de Savoie sont á base de grains de maïs cueillis verts, la grünkern soppe d'Autriche de même que de nombreux gâteaux d'Afrique du nord. (note FAS)

\section{RÉSUMÉS}

Le maïs, actuellement la céréale la plus cultivée au monde, est né au Mexique, il y a environ 10000 ans, à partir de la domestication de plantes sauvages connues sous le nom de téosintes. C'est là qu'il s'est diversifié, en se dispersant sur tout le continent américain, atteignant, à la fin $\mathrm{du} \mathrm{Xv}^{\mathrm{e}}$ siècle, diverses latitudes de l'Ancien Monde. Au Mexique, les agriculteurs, leurs familles et leurs communautés conservent une immense diversité de maïs indigènes qu'ils cultivent dans des conditions environnementales très diverses et principalement pour des utilisations alimentaires. Cette céréale constitue la base alimentaire de la population et avec elle se sont développées de nombreux usages culinaires et expressions culturelles. Certains aspects de cette diversité au Mexique sont abordés dans cet article.

Maize is currently the most widely produced cereal in the world and it was domesticated in Mexico, approximately 10,000 years ago, from a wild grass known as teosinte. In Mexico, it became highly diversified, spreading throughout the American Continent and in the $6^{\text {th }}$ century it reached various latitudes of the old World. In Mexico, farmers, their families and communities maintain an enormous diversity of native maize, which they cultivate in a wide range of environmental conditions mainly for food uses. Maize constitutes the fundamental source of food for the population and a wide diversity of culinary uses and cultural expressions have been developed around it. Some aspects of this diversity in Mexico are discussed here.

El maíz, actualmente el cereal con mayor producción a nivel mundial y se originó en México, hace aproximadamente 10,000 años, a partir de la domesticación de unos pastos silvestres conocidos como teocintles. Aquí se diversificó, dispersándose a lo largo del Continente Americano, alcanzando hacia el siglo VI diferentes latitudes del Viejo Mundo. En México, los agricultores, sus familias y comunidades, mantienen una enorme diversidad de maíces nativos, que cultivan en un amplio rango de condiciones ambientales y para usos principalmente alimenticios; este grano constituye la fuente básica de alimentación de la población, y en torno a él se desarrolla una extensa diversidad de usos culinarios y expresiones culturales. Se comentan aquí algunos aspectos de esta diversidad en México. 
INDEX

Index géographique : Mexique

Palabras claves : razas de maíz, teocintle, diversidad, ambiente, usos alimenticios, milpa

Keywords : races of maize, teosinte, crop diversity, environment, food uses, milpa

Mots-clés : races de maïs, téosinte, diversité, environnement, utilisations alimentaires, milpa

\section{AUTEUR}

\section{CECILIO MOTA CRUZ}

Posgrado en Ciencias de la Sostenibilidad, Universidad Nacional Autónoma de México, campus

Morelia - cecilio.mota.cruz@gmail.com 